\title{
Mouse models of follicular and papillary thyroid cancer progression
}

\section{Marika A. Russo ${ }^{\dagger}$, Valeria G. Antico Arciuch ${ }^{\dagger}$ and Antonio Di Cristofano*}

Department of Developmental and Molecular Biology, Albert Einstein College of Medicine, Bronx, NY, USA

\section{Edited by:}

Francesca Carlomagno, Universita'

degli Studi di Napoli Federico II, Italy

\section{Reviewed by:}

Steven I. Sherman, University of Texas M.D. Anderson Cancer Center, USA Rosa Marina Melillo, University of Naples Federico II, Italy

\section{*Correspondence:}

Antonio Di Cristofano, Department of Developmental and Molecular

Biology, Albert Einstein College of

Medicine, Price Center for Genetic

and Translational Medicine, 1301

Morris Park Avenue, Room 302,

Bronx, NY 10461, USA.

e-mail: antonio.dicristofano@

einstein.yu.edu

${ }^{+}$Marika A. Russo and Valeria G. Antico Arciuch have contributed equally to this work.
A significant number of well-differentiated thyroid cancers progress or recur, becoming resistant to current therapeutic options. Mouse models recapitulating the genetic and histological features of advanced thyroid cancer have been an invaluable tool to dissect the mechanisms involved in the progression from indolent, well differentiated tumors to aggressive, poorly differentiated carcinomas, and to identify novel therapeutic targets. In this review, we focus on the lessons learned from models of epithelial cell-derived thyroid cancer showing progression from hyperplastic lesions to locally invasive and metastatic carcinomas.

\section{Keywords: thyroid, cancer, mouse, progression}

\section{INTRODUCTION}

The thyroid gland is the most common target of neoplastic transformation among endocrine organs. Contrary to most tumor types, the global incidence of thyroid cancer has been steadily growing in recent years. Most thyroid cancers derive from the thyrocytes, the epithelial cells that delineate the thyroid follicles, and include well-differentiated tumors, such as papillary and follicular carcinomas, as well as poorly differentiated and anaplastic carcinomas. Although well-differentiated thyroid cancers have generally a good prognosis and can be effectively managed through a combination of surgery and radioactive iodine treatment, a number of them will progress or recur, becoming resistant to current therapeutic options. On the other hand, poorly differentiated and anaplastic tumors often derive from pre-existing well-differentiated lesions and are responsible for the vast majority of thyroid cancer-related deaths, thanks to their very poor response to therapy.

In order to design rational approaches to these otherwise unresponsive tumors, we need to better define and understand the molecular mechanisms leading to progression from indolent, well-differentiated tumors to aggressive cancers. One strategy to accomplish this task is to generate model systems that more or less faithfully recapitulate in vivo what has been learned from molecular pathology studies on patient material. These models can then be used to dissect in a physiological setting the pathways deregulated as a consequence of specific genetic alterations.

Advances in the genetic manipulation of the mouse genome have facilitated the generation of models harboring defined genetic alterations that can be controlled both temporally and spatially. Although their use in preclinical studies is often hampered by the time needed to develop tumors, by the generally low metastasis incidence, and by some biological differences between mice and humans in drug metabolism, mouse models of cancer have been an invaluable tool to study gene function, interaction between pathways, and the specific mechanisms that play a role in tumor progression.

In this review, we will focus on what we have learned from mouse models of thyroid cancer that display progression from hyperplastic lesions to locally invasive and metastatic carcinomas.

\section{PTC PROGRESSION MODELS}

Papillary thyroid carcinoma (PTC) is the most common subtype among differentiated thyroid tumors and represents up to $80 \%$ of all malignant thyroid cancers. Patients affected by PTC are effectively treated with thyroidectomy followed by radioactive iodine ablation (DeGroot et al., 1990). After surgery the survival rate and the therapeutic outcomes of PTC patients are favorable. However, up to $10 \%$ of PTC patients can exhibit lymph node metastases or distant metastases at the time of thyroid ablation that are associated with a significant increase in morbidity (Huang et al., 2011). The etiology of papillary carcinomas is often correlated with a diet poor in iodine and with radiation exposure. In particular there are evidences that survivors of cancers of various organs whose tumor had been treated with radiation developed, later on in their life, papillary thyroid cancers (LiVolsi, 2011). Older age, male sex, large size, and extrathyroidal extension can be a contributing 
factor for a negative prognosis, although they are not entirely reliable in predicting tumor recurrence, metastasis, and cancer-related death. The diagnosis for PTCs is based on conventional tumor morphology and on the WHO histological classification (Kakudo et al., 2011). This classification is based on nuclear features such as ground glass appearance, pale staining, inconspicuous nucleoli, large size, and irregular outline together with the presence of vascular core, psammoma bodies, fibrous stroma, squamous metaplasia, and presence of follicles (LiVolsi and Baloch, 2004). A minority of PTCs progress from well-differentiated carcinoma to either poorly or undifferentiated carcinoma, an event associated with a marked reduction in survival. However, whether certain subtypes of papillary carcinoma are associated with a more aggressive clinical behavior is still unclear. Moreover the invasive features are often difficult to predict only from the histological analysis. There is increasing evidence suggesting that PTCs represents a rather heterogeneous group of tumors, and that specific genetic alterations may not only determine the distinct global expression profile of the tumor, but also influence its histologic variants and tumor behavior (Giuffrida and Gharib, 2000).

Over the past decade, the genetic and epigenetic basis for PTCs has been defined and distinct activating mutations of oncogenes have being described together with epigenetic silencing of tumor suppressor genes (Kimura et al., 2003). The earliest, most common, and best-characterized somatic genetic alterations in PTCs are the RET/PTC rearrangement (Santoro et al., 1993), the TRK$T 1$ mutation, and the $B R A F^{\mathrm{V} 600 \mathrm{E}}$ point mutation. They appear to be mutually exclusive, but it has been demonstrated that they work along the same signaling cascade that starts with the phosphorylation of RET on tyrosine 1062, and sequentially triggers RAS, BRAF, and ERK stimulation. Moreover the three activated oncoproteins induce largely overlapping gene expression signatures (Melillo et al., 2005).

The acquisition of a migratory phenotype and the loss of tumor suppressor genes such as TP53, lead to progression toward poorly differentiated (PDTC), and undifferentiated thyroid carcinoma (ATC; Giordano et al., 2005).

Transgenic mice carrying the aforementioned mutations have been instrumental in increasing our understanding of the mechanisms that are responsible for the progression from PTC to PDTC or ATC.

\section{RET/PTC MODELS}

$R E T / P T C$ mutations are frequently detected in PTC, particularly in radiation-induced PTC. The RET/PTC rearrangement is the second most common type of genetic alteration known to occur in thyroid papillary carcinomas (Pierotti et al., 1996).

The RET proto-oncogene encodes a transmembrane glycoprotein belonging to the receptor tyrosine kinase (RTK) family. It is the receptor for growth factors belonging to the glial cell linederived neurotrophic factor (GDNF) family. The fusion of the $3^{\prime}$-terminal kinase-encoding domain of RET to the $5^{\prime}$-terminal regions of heterologous genes leads to the formation of a chimeric oncogene. There are at least 15 different $R E T / P T C$ rearrangements but $R E T / P T C 1$ and RET/PTC3 are the most prevalent variants. $R E T / P T C 1$ originates from the fusion between RET and the H4 gene (Grieco et al., 1990), while RET/PTC3 originates from the RET-RFG (also designed as ELE1, NCOA4, ARA70) fusion (Santoro et al., 1994). All the other rearrangement variants have been isolated just in rare cases (Fusco and Santoro, 2007).

While the RET proto-oncogene products localize in the membrane fraction and are not phosphorylated in the absence of a ligand, the RET/PTC product localizes in a soluble cytoplasmic fraction and is constitutively phosphorylated (Ishizaka et al., 1992). RET triggers several intracellular signaling cascades, which regulate survival, differentiation, proliferation, migration, and chemotaxis through the activation of targets such as the Ras/ERK kinase, PI3 kinase/AKT, p38MAP kinase, PLC- $\gamma$, JNK, STAT, ERK5, and Src signaling pathways (Sariola and Saarma, 2003).

$R E T / P T C 3$ is more efficient than RET/PTC1 in promoting proliferation of cultured thyroid cells. Accordingly, transgenic mice expressing the human RET/PTC1 gene under the control of the bovine thyroglobulin promoter develop PTCs, demonstrating that $R E T / P T C$ oncogenes are able to initiate thyroid carcinogenesis (Santoro et al., 1996). However, invasive cancer does not occur in these models. On the other hand, transgenic mice expressing the human RET/PTC3 gene under the control of the same bovine thyroglobulin promoter develop papillary carcinoma with metastatic spread in selected cases (Jhiang et al., 1998; Powell et al., 1998). The severity of disease varies markedly between high- and low-copy number founder lines. High-copy lines have dysplastic thyroid glands at birth and develop carcinomas as young as 4 days of age, as compared with 1-6 months of age in the low-copy line (Cho et al., 1999).

RET/PTC1 mice maintained on a low iodine diet present a persistent elevation of thyroid-stimulating hormone (TSH) levels and enhanced tumorigenesis. However, the high TSH levels of the RET/PTC1 transgene are a disadvantage of this model, because chronic TSH stimulation is generally not involved in papillary carcinoma development in humans (Williams et al., 2004), although recent data seem to suggest a correlation between TSH levels and tumor size (Zafon et al., 2012).

One possibility that could explain the limited ability of small tumors with RET gene rearrangements to progress, is the proapoptotic activity of RET/PTC. It has been shown that during tumor progression, secondary events, such as overexpression of the anti-apoptotic protein Bcl-2 or activation of other cell survival pathways (Gimm et al., 2001), including overexpression of AKT or downregulation of PTEN, can be selected to suppress RET/PTCinduced apoptosis and to promote the expansion of the neoplastic clones (Castellone et al., 2003).

An additional event that could suppress apoptosis and allow tumor progression is loss of $\mathrm{p} 53$. In general, lack of functional p53 protein alone is not sufficient to induce a malignant phenotype (Battista et al., 1995), however, p53 loss in the presence of RET/PTC1 mutation contributes to the progression and metastasis formation of thyroid epithelial neoplasms. Transgenic mice expressing RET/PTC1 under the control of the bovine or rat thyroglobulin promoters in a $p 53^{-/-}$background develop anaplasticlike tumors. These tumors are bilateral, and TSH-responsive, with cystic and solid regions. The solid regions are composed of spindle cells, which is a common feature of ATCs in human (La Perle et al., 2000). One caveat of this model is that compound mutant 
mice often died because of extrathyroidal tumors, due to the "nontissue-specific" p53 mutation. Unfortunately a thyroid-restricted

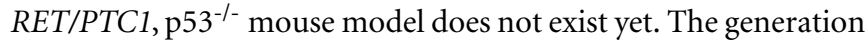
of this mouse model would likely allow the mice to live enough for metastases to develop.

The more aggressive RET/PTC3 transgenic mice develop follicular cell hyperplasia and a solid variant of PTC by the age of 6 months (Powell et al., 1998). Less than 10\% of these mice develop metastases to cervical lymph nodes. Interestingly, RET/PTC3 thyroids expressed proinflammatory genes and cytokines such as Cox-2, Gmcsf, Il1 $\alpha$, Il1 $\beta$, Mcp1, Il6, and Tnf $\alpha$, and recruited macrophages to the lesions, a process known to aid tumor progression (Russell et al., 2004). The RET/PTC3-induced thyroid tumors do not dedifferentiate into a more aggressive phenotype as often as seen in human patients with RET/PTC3 chromosomal rearrangements. Intercross of Tg-RET/PTC3 transgenic mice with $p 53^{-/-}$mice results in earlier tumor onset, with microcarcinoma formation by 3 months of age and the development of larger primary tumors compared to the $p 53$ wild-type mice. However metastases are still rare (Powell et al., 2001).

\section{TRK-T1 MODELS}

The TRK family of oncogenes results from a genetic fusion of the $3^{\prime}$ end of NTRK 1 to the $5^{\prime}$ end of several partner genes (Pierotti et al., 1996). In particular the TRK oncogene results from the inversion of chromosome 1 that joins the $5^{\prime}$ end of Tropomyosin (TPM3) to NTRK1 (Bongarzone et al., 1989). TRK-T1, -T2, and -T4 are generated from inversions of chromosome 1 that join the $5^{\prime}$ end of TPR to the $3^{\prime}$ end of NTRK1. A rearrangement involving the genes TFG and NTRK1 results in the family member TRK-T3.

NTRK1-related translocations have a reported incidence of about $12 \%$. In vitro, the TRK-T1 oncogene transforms NIH3T3 cells (Greco et al., 1992). The only described mouse model of NTRK1 rearrangement is a transgenic model of TRK-T1 under the control of the bovine thyroglobulin promoter. More than $50 \%$ of the TRK-T1 mice show thyroid epithelial cell hyperplasia which progresses to PTCs in animals over 7 months of age, and has the histopathological features observed in its human counterpart.

Few thyroid tumors in TRK-T1 mice developed lessdifferentiated solid regions during 24 months of observation, and none of the tumors metastasized. It is clear, as it happens in $R E T / P T C$ mice, that while TRK-T1 predisposes mice to develop PTCs, additional genetic mutations are required to evolve into more aggressive tumors (Russell et al., 2000). Thus, the TRK$T 1$ fusion gene may allow thyroid follicular epithelial cells to survive and accumulate other genetic abnormalities. A representative example of this concept is the cross between TRK-T1 mice and $p 27^{-1-}$ mice. Decreased expression and altered subcellular localization of p27 have been observed in thyroid cancer (Motti et al., 2005) and a correlation has been found between the overexpression of the TRK-T1 transgene and $p 27$ deletion in thyroid carcinomas. The $p 27$ mutation increases the malignant phenotype of mice expressing the TRK-T1 oncogene: the compound mutants show an increased number of carcinomas with a shorter latency and an increased proliferation rate (Fedele et al., 2009).

\section{BRAF $^{V 600 E}$ MODELS}

$B R A F$ is a member of the RAF kinase family. The BRAF gene, encoding a cytosolic serine-threonine protein kinase, serves as an immediate downstream effector of RAS. BRAF transmits signals from RAS to the mitogen-activated protein kinase (MAPK) pathway through MEK and ERK. Over 30 BRAF mutations associated with human cancers have been described, and the majority is located within the kinase domain. Common BRAF somatic activating mutations have been identified in melanomas $(70 \%$ prevalence), and colorectal and ovarian cancers (15\%), as well as in thyroid cancers ( $>40 \%$ papillary carcinomas). BRAF mutations are particularly common in melanomas and thyroid cancer. The growth of melanocytes and thyrocytes is positively regulated by cAMP. In particular cAMP activates MEK1 and ERK through mechanisms that converge on BRAF. Thus, BRAF is the key RAF isoform transducing cAMP-dependent growth signal in both these cell types (Busca et al., 2000), and this, together with the higher basal activity and simpler activation mechanism of BRAF compared to ARAF and CRAF (Maurer et al., 2011), can reasonably explain their vulnerability to transformation by $B R A F$ activating mutations (Kimura et al., 2003).

The BRAF mutation found in the vast majority of thyroid cancers is a thymine-to-adenine transversion at nucleotide 1796 (T1796A), resulting in a valine-to-glutamic acid substitution at amino acid 600 (V600E; Fukushima et al., 2003). BRAF point mutations are found at all stages of progression, from microcarcinomas to poorly differentiated and anaplastic carcinomas, suggesting that this mutation is responsible for the initiation of the transformation process.

Thyroid-specific expression of $B R A F^{\mathrm{V} 600 \mathrm{E}}$ induces goiter that progresses to invasive PTC with tall-cell features. After 22 weeks of age, mice develop aggressive thyroid papillary carcinomas with a high frequency of invasion into blood vessel, thyroid capsule, and skeletal muscle (Knauf et al., 2005). BRAF-mutant papillary carcinomas have a high degree of lymphocytic infiltration within the tumor, but less frequent psammoma bodies as compared to tumors harboring RET/PTC rearrangements. Furthermore, $B R A F$-mutant tumors have a different gene expression profile, compared to RET/PTC tumors, with a significant deregulation of genes related to the innate immune response. There is a strong correlation between increased tumor-associated macrophages (TAMs) and histologic grade, and between TAMs, tumor invasiveness, and decreased cancer-related survival in PDTC. BRAF ${ }^{\mathrm{V} 600 \mathrm{E}}$ mice indeed show a high density of TAMs, suggesting that TAMs promote papillary thyroid cancer progression (Ryder et al., 2008).

The $B R A F^{\mathrm{V} 600 \mathrm{E}}$ mutation induces also the expression of genes involved in matrix remodeling, which could account in part for the greater predisposition of PTC with BRAF mutation to invade surrounding tissues (Mesa et al., 2006). In human patients, PTCs harboring $B R A F^{\mathrm{V} 600 \mathrm{E}}$ show a more aggressive clinicalpathologic behavior, with extrathyroidal extension and a significant increase in MMP-2, MMP-9, and ICAM-1 protein levels, suggesting that these proteins may play a role in PTC progression (Frasca et al., 2008). Furthermore, high levels of CXCR4 expression were found in $B R A F^{\mathrm{V} 600 \mathrm{E}}$-positive PTCs, and CXCR4 expression was associated with thyroid capsule infiltration and extrathyroidal 
extension (Torregrossa et al., 2011). These findings await in-depth mechanistic analysis in the $B R A F^{\mathrm{V} 600 \mathrm{E}}$ mouse model.

Finally, an expression profile study of murine PDTCs derived from $B R A F^{\mathrm{V} 600 \mathrm{E}}$ transgenic mice showed an unequivocal signature of epithelial-to-mesenchymal transition (EMT; Knauf et al., 2011). EMT involves changes in epithelial cells that disassemble their junctional structures, express mesenchymal proteins, remodel their extracellular matrix, lose polarity, and become more migratory. Thus, this model will allow a more mechanistic approach to the problem of thyroid cancer dedifferentiation and progression to poorly differentiated and anaplastic tumors.

Although this first mouse model of $B R A F^{\mathrm{V} 600 \mathrm{E}}$-positive PTC recapitulates the phenotype of human PTCs, it displays severe hypothyroidism that is not usually present in humans. A recent paper describes a novel inducible PTC model (Thyro::CreER ${ }^{T 2}$; $B R a f^{C A}$ ) in which widespread Cre-induced BRAF activation generates the same tumor and hypothyroid phenotype as the older model. However, stochastic tamoxifen-independent Cre activity induces localized lesions without concurrent hormonal derangement. Therefore this model may be, in some aspects, a more accurate model of human PTC (Charles et al., 2011).

The recent development of novel small-molecule inhibitors targeting $\mathrm{BRAF}^{\mathrm{V} 600 \mathrm{E}}$ may provide selective and rational advantages for the treatment of patients with PTC harboring this mutation. In particular, two Plexxikon compounds, PLX4720 and PLX4032, are novel, orally available selective small-molecule inhibitors of $\mathrm{BRAF}^{\mathrm{V} 600 \mathrm{E}}$ that have been specifically designed to insert into the ATP-binding site and trap oncogenic $\mathrm{BRAF}^{\mathrm{V} 600 \mathrm{E}}$ in an inactive conformation. These compounds have shown an important effect in a cohort of melanoma patients (Bollag et al., 2010).

In thyroid tumors, in vitro treatment of $B R A F^{\mathrm{V} 600 \mathrm{E}}$-positive thyroid cancer cell lines with PLX4720 resulted in cell cycle arrest, whereas RET/PTC1 and RAS mutated thyroid cancer cell lines were resistant to inhibition even at high concentrations (Salerno et al., 2010). Furthermore, PLX4720 markedly inhibited tumor growth and metastasis in an orthotopic mouse model of human ATC harboring BRAF $F^{\mathrm{V} 600 \mathrm{E}}$ (Nucera et al., 2011). PLX4032 is being tested in human $B R A F^{\mathrm{V} 600 \mathrm{E}}$ carriers. Early results show one partial response and two patients with a brief stable disease among the three PTC patients analyzed in a phase I trial (Flaherty et al., 2010). Accordingly, evidence is accumulating that $B R A F^{\mathrm{V} 600 \mathrm{E}}$ tumors rapidly develop resistance to BRAF inhibitors (Nazarian et al., 2010). In vivo studies using the aforementioned mouse models will shed more light on the mechanisms implicated in resistance development, and on the possibility of overcoming resistance by targeting the pathways involved.

\section{FTC PROGRESSION MODELS}

Follicular thyroid carcinoma (FTC) represents the second largest subtype of thyroid malignancies, and is more prevalent in areas of dietary iodine deficiency (Schlumberger, 1998). FTC patients have a poorer outcome than those affected with PTC since they are less likely to take up radioactive iodide for imaging and therapeutic ablation (Jonklaas et al., 2006). Histologically, FTCs display variable morphology ranging from small/medium-sized follicles containing colloid to trabecular or solid growth pattern (Schlumberger, 1998). It is extremely rare for a FTC to be composed of macrofollicles (Fonseca et al., 2006).

The major molecular features of FTC are the prominence of aneuploidy and the high prevalence of RAS mutations and of $P A X 8-P P A R \gamma$ rearrangements, the latter as a result of a chromosome 2;3 translocation (DeLellis, 2004). The PAX8-PPAR $\gamma$ rearrangement leads to in-frame fusion of exon 7, 8, or 9 of $P A X 8$ on 2q13 with exon 1 of PPAR $\gamma$ on 3p25 (Kroll et al., 2000). This translocation creates a fusion gene composed by the DNA-binding domain of the thyroid transcription factor $P A X 8$ and domains A to $\mathrm{F}$ of the nuclear receptor PPAR $\gamma$ (Eberhardt et al., 2010). The exact mechanism by which this rearrangement leads to a carcinogenic phenotype is not fully understood. It appears as though the PAX8-PPAR $\gamma$ chimeric protein inactivates the wild-type PPAR $\gamma$, which is a putative tumor suppressor (Suh et al., 1999; Chang and Szabo, 2000).

Follicular neoplasms are also often characterized by PI3K/AKT alterations. Phosphorylation of AKT, the key player in this pathway, is far more frequent than that of ERK in FTCs (Xing, 2010). The aneuploid pattern and the various molecular alterations detected in FTCs support the assumption that the development of such tumors is the endproduct of multiple oncogenic steps, thus justifying their usual appearance as single neoplasms (Fagin, 2002).

Most models for FTC were established based on the genetic alterations described in human tumors such as Ras mutations and $P A X 8-P P A R \gamma$ rearrangement. However, mouse models based on these genetic alterations have failed to fully recapitulate human FTC. Instead, genetically engineered models carrying a thyroid hormone receptor $\beta$ mutant (TR $\beta^{\mathrm{PV} / \mathrm{PV}}$ ) and deletion of the Pten tumor suppressor have become the tool of choice to study the development of FTC.

\section{TR $\beta^{\text {PV/PV }}$ MODELS}

Thyroid hormone receptors (TRs) are ligand-dependent transcription factors that have a central role in cell proliferation, differentiation, and apoptosis. They are members of the steroid hormone/retinoic acid nuclear receptor superfamily. Two genes, $T R \alpha$ and TR $\beta$, located on human chromosome 17 and 3, respectively, encode for four thyroid hormone (triiodothyronine T3) binding receptors (TR $\alpha 1, \operatorname{TR} \beta 1, \mathrm{TR} \beta 2$, and $\mathrm{TR} \beta 3$ ) and two nonT3-binding receptors (TR $\alpha 2$ and $T R \alpha 3$ ). These TRs are expressed in a tissue-dependent and developmentally regulated pattern (Cheng, 2000). Mutations of the TRs can cause a potent dominant negative action (Lin et al., 1999). Furthermore, multiple mutations in both TR $\alpha 1$ and TR $\beta 1$, with impairment in T3 and DNA binding and loss of transcriptional activity, were detected in human renal clear cell carcinoma (Kamiya et al., 2002). Unusually high frequencies of mutations in TR $\beta 1$ and TR $\alpha 1$ were also found in a subset of human PTC (93.75 and 62.25\%, respectively, of 16 tumors examined; Puzianowska-Kuznicka et al., 2002).

Kaneshige et al. (2000) generated a mutant knock-in mouse expressing a potent dominant negative TR $\beta 1$ mutant, $P V\left(T R \beta^{\mathrm{PV}}\right.$ mice). The $P V$ mutation was identified in a patient with thyroid hormone resistance syndrome (RTH; Parrilla et al., 1991; Weiss and Refetoff, 2000). RTH is a genetic disease caused by mutations 
of the TRß gene (Weiss and Refetoff, 2000). Most patients with $\mathrm{RTH}$ are heterozygotes with only one mutant TR $\beta$ allele (Weiss and Refetoff, 2000). Patients with RTH exhibit dysfunction of the pituitary-thyroid axis, with high circulating levels of TSH and thyroid hormones (T3 and thyroxine T4; Weiss and Refetoff, 2000). PV has a unique mutation in exon 10, a C-insertion at codon 448 , which causes a frameshift of the carboxy-terminal 14 amino acids of TR $\beta 1$, resulting in total loss of T3-binding and transcriptional activation (Meier et al., 1992).

$T R \beta^{P V}$ mice faithfully reproduce human $\mathrm{RTH}$ because they exhibit mild disruption of the thyroid-pituitary axis and a severe dysfunction of the pituitary-thyroid axis (Kaneshige et al., 2000). In addition, $T R \beta^{P V / P V}$ homozygotes develop follicular cell hyperplasia by 3 weeks of age and invasive FTCs by $4-5$ months of age. They also display metastases to the lungs and heart by 5 months of age, and the metastases often have foci of anaplasia consisting of spindle-shaped cells (Suzuki et al., 2002). This mouse model offers a fairly good recapitulation of human follicular carcinoma arising from hyperplastic goiter, but it differs in that these mice have elevated circulating T3 and T4 levels, while human FTCs are infrequently functional (Kaneshige et al., 2000).

Kato et al. (2004) crossed $T R \beta^{P V}$ mice with $T R \beta^{-/-}$mice. As $T R \beta^{P V /-}$ mice aged, they also spontaneously developed FTC after progression from hyperplasia, with local invasion, anaplasia, and metastasis to the lungs (Kato et al., 2004). The pathological progression of thyroid carcinoma in $T R \beta^{P V /-}$ mice was identical to that in $T R \beta^{P V / P V}$ mice, and the patterns in the alteration of signaling pathways were also similar to those observed in $T R \beta^{P V / P V}$ mice during thyroid carcinogenesis (Kato et al., 2004). These results point out that TR $\beta$ may function as a tumor suppressor, since, in the absence of a wild-type allele, the $P V$ mutation in one TR $\beta$ allele is sufficient for the mutant mice to spontaneously develop FTC.

One of the overexpressed genes in mice carrying the $T R \beta^{P V / P V}$ genotype is the pituitary tumor-transforming gene (PTTG), which has been previously associated with tumorigenesis (Ramaswamy et al., 2003). To evaluate the role of PTTG in thyroid carcinogenesis, Kim et al. (2007b) analyzed the offspring of $T R \beta^{P V}$ mice crossed with mice lacking PTTG $\left(P T T G^{-/-}\right.$mice). The thyroids of $T R \beta^{P V / P V} P T T G^{-/-}$mice resulted significantly smaller than those of $T R \beta^{P V / P V}$ mice, with a decrease in thyroid proliferation. Histological analysis showed no difference in FTC occurrence between $T R \beta^{P V / P V}$ and $T R \beta^{P V / P V} ; P T T G^{-/-}$mice, which indicates that PTTG deletion does not prevent the initiation of FTC. However, $T R \beta^{P V / P V}, P T T G^{-/-}$mice exhibited a significant decrease in vascular invasion and less development of lung metastasis as they aged. CD31 staining also showed a decrease in vessel density in $T R \beta^{P V / P V} ; P T T G^{-/-}$versus $T R \beta^{P V / P V}$ thyroids, highlighting the dual roles of PTTG as a regulator of thyroid growth and contributor of tumor progression (Kim et al., 2007b).

Kim et al. (2007a) also tested the role of gelsolin, an actinregulatory protein, which had been previously found downregulated in the mutant mice and in many other cancers such as breast (Winston et al., 2001), bladder (Tanaka et al., 1995), lung (Dosaka-Akita et al., 1998), and prostate (Lee et al., 1999). The results of these studies showed that there was an age-dependent reduction of gelsolin protein abundance in $T R \beta^{P V / P V}$ mice as tumorigenesis progressed. Knockdown of gelsolin by small interfering RNA resulted in increased tumor cell motility whereas an increase in gelsolin expression led to decreased cell motility (Kim et al., 2007a). Further biochemical analysis demonstrated that gelsolin physically interacts with the DNA-binding domain TR $\beta 1$ or PV in vivo and in vitro, and that the interaction with $\mathrm{PV}$ reduces gelsolin's binding to actin, leading to disarrayed cytoskeletal architectures (Kim et al., 2007a). These results suggest that PVinduced alterations of the actin/gelsolin cytoskeleton contributes to increased cell motility that contributes to the local tumor progression and metastatic potential of thyroid carcinogenesis.

Since the $T R \beta^{P V / P V}$ mice exhibit highly elevated TSH levels, Lu et al. (2010) crossed the TR $\beta^{P V / P V}$ mice with TSHR knockout mice (TSHR ${ }^{-/-}$mice) to eliminate the effect of TSH-TSHR signaling during carcinogenesis. They found that the thyroid of $T R \beta^{P V / P V} T_{S S R}{ }^{-/-}$mice exhibited impairment in growth and did not develop tumors. However, TSH signaling, while necessary, was not sufficient for transformation, since wild-type mice treated with the goitrogen PTU had a 9.1-fold higher serum TSH level than $T R \beta^{P V / P V}$ mice, but the degree of thyroid pathology was less than that of $T R \beta^{P V / P V}$ mice at the same age (Lu et al., 2010).

The PI3K/AKT pathway is activated in both the thyroid and metastatic lesions of the TR $\beta^{P V / P V}$ mouse model (Kim et al., 2005). Since the activation of the PI3K/AKT signaling cascade contributes to thyroid carcinogenesis, this pathway becomes a potential therapeutic target in FTC. When the TR $\beta^{P V / P V}$ mice were treated with LY294002 (LY), a potent PI3K inhibitor, a decrease in cyclin D1 expression was observed (Furuya et al., 2007). Concomitantly, the mice displayed an increase in $\mathrm{p} 27^{\mathrm{Kip} 1}$ expression to inhibit thyroid tumor growth and reduce tumor cell proliferation. LY treatment increased caspase- 3 and decreased phosphorylated-BAD to induce apoptosis. In addition, LY treatment reduced the AKT-matrix metalloproteinase 2 signaling with a decrease in cell motility to block metastatic spread of thyroid tumors (Furuya et al., 2007). Therefore, this treatment effectively prolonged the survival of $T R \beta^{P V / P V}$ mice, providing the first preclinical evidence of the in vivo efficacy of PI3K inhibition in the treatment of FTC.

More recently, tumor development, progression, and metastasis were analyzed in the TR $\beta^{P V / P V} ; A k t 1^{-/-}$mouse model (Saji et al., 2011). PV-dependent thyroid hyperplasia occurred in both groups Akt1 WT and KO mice; however, the thyroid size was greater in the WT mice. On the other hand, thyroid cancer development was delayed in the $\mathrm{KO}$ mice and the degree of tumor invasiveness was reduced (Saji et al., 2011). The WT mice displayed pulmonary metastases at 12 and 15 months of age, while $\mathrm{KO}$ mice did not. In spite of sustained expression of Akt2 or Akt3, pAkt levels were decreased, suggesting that thyroid cancer development and progression in $T R \beta^{P V / P V}$ mice are Akt1-dependent.

Along the same pathway, to assess how Pten deregulation contributes to the PV phenotype, TR $\beta^{P V / P V}, \mathrm{Pten}^{+/-}$mice were generated and analyzed (Guigon et al., 2009). These studies demonstrated that Pten deficiency accelerated the progression of thyroid tumors and increased the occurrence of metastases to the lungs in the PV mice, thereby significantly reducing their survival as compared with $T R \beta^{P V / P V}$, Pten $^{+/+}$mice (Guigon et al., 2009). AKT activation was concomitantly increased by twofold in 
$T R \beta^{P V / P V}$, Pten $^{+/-}$thyroids, leading to increased activity of the downstream mammalian target of rapamycin (mTOR)-p70S6K and decreased activity of the forkhead family member FOXO3a. In addition, cyclin D1 expression was increased, and apoptosis was decreased as indicated by increased expression of nuclear factor- $\kappa \mathrm{B}(\mathrm{NF}-\kappa \mathrm{B})$ and decreased caspase-3 activity (Guigon et al., 2009). Guigon et al. also analyzed the effect of a treatment with a specific mTORC1 inhibitor (RAD001) in the TR $\beta^{P V / P V}, \mathrm{Pten}^{+/-}$ mouse model. Although the treatment did not prevent capsular and vascular invasion and the occurrence of lung metastases, it considerably reduced thyroid tumor growth, there by prolonging the mice's life span. RAD001 induced a significant decrease in cell proliferation that was linked to the reduced amount and altered activity of key regulators of cell cycle progression (Guigon et al., 2010).

The steroid receptor activator-3 (SRC-3) is a member of the p160 family that complexes with members of the steroid/thyroid hormone receptor superfamily to modulate their transcriptional activity (Liao et al., 2002; Lonard and O'Malley, 2005). It is amplified in breast and ovarian cancer (Anzick et al., 1997) and overexpressed and/or amplified in other steroid hormone-sensitive tumors, such as prostate cancer and meningioma, as well as steroid hormone-independent tumors, such as pancreatic cancer, colorectal carcinoma, and hepatocellular carcinoma (Yan et al., 2006). Transgenic mice overexpressing SRC-3 display many types of malignancy in several tissues, such as mammary gland, pituitary, uterus, lung, and liver, through activation of the insulin growth factor (IGF)/AKT signaling (Torres-Arzayus et al., 2004). To determine its effects on thyroid carcinogenesis, Ying et al. (2008) crossed $T R \beta^{P V / P V}$ mice with $S R C-3$ null mice to evaluate thyroid tumor development and progression. TR $\beta^{P V / P V}$ mice deficient in SRC$3\left(T R \beta^{P V / P V} S R C-3^{-/}\right.$mice) exhibited significantly increased survival, decreased thyroid tumor growth, delayed tumor progression, and lower incidence of distant metastasis as compared with $T R \beta^{P V / P V}, S R C-3^{+/+}$mice (Ying et al., 2008). Additional in vivo and in vitro analyses showed that SRC-3 deficiency leads to inhibition of cell cycle progression by controlling the expression of E2F1, could induce apoptosis through the control of the expression of $\mathrm{Bcl}-2$ and caspase-3, and finally could suppress neovascularization and metastasis (Ying et al., 2008).

\section{PTEN-I-MODELS}

Despite all the correlative data regarding the PI3K/AKT signaling cascade in the control of normal thyroid function and the link between its deregulation and thyroid disease, the aforementioned pathogenetic models still lacked direct in vivo evidence supporting their validity. To address these issues, we have generated a mouse strain in which the Pten gene is selectively deleted in the thyroid follicular cells by Cre-mediated recombination. This leads to constitutive activation of the PI3K/AKT pathway and reproduces the genetic events taking place in the nodular lesions and thyroid carcinomas developing in Cowden disease patients, who carry a heterozygous germline mutation in PTEN. Pten mutant mice develop from birth diffuse goiter characterized by extremely enlarged follicles, in the presence of normal TSH and T4 hormone levels (Yeager et al., 2007). A unique feature of this model is the differential proliferative advantage of mutant thyrocytes between genders, mimicking the increased incidence of thyroid disease in women (Yeager et al., 2007; Antico-Arciuch et al., 2010).

Surprisingly, goitrogen treatment did not cause a substantial increase of the mutant thyroid size and increased only to some extent the proliferation index of the female thyrocytes, suggesting that a relevant part of the TSH-induced proliferation signals are conducted through the PI3K/AKT cascade (Yeager et al., 2007), converging on mTOR (Yeager et al., 2008).

Complete loss of Pten leads to invasive tumors in over 50\% of the mutant females and $35 \%$ of the mutant males aged 1 year (Antico-Arciuch et al., 2010). These data show that Akt activation is sufficient, in vivo, to induce thyroid hyperplasia and diffuse colloid goiter in young mice by increasing the thyroid mitotic index, and that it needs additional genetic alterations for neoplastic transformation to occur in older mutants.

Thyroid cancer originating from the follicular epithelium often displays activating mutations of Ras family members (Shi et al., 1991). Although several transgenic approaches have been used in the past to define the molecular mechanisms of Ras-mediated thyroid transformation, it is now clear that supraphysiologic expression in transgenic systems does not resemble the activity of oncogenic Ras when expressed at endogenous levels (Feunteun et al., 1997; Tuveson et al., 2004; Vitagliano et al., 2006).

The frequencies and overlap of genetic alterations in the PI3K and Ras/MAPK cascades increase with progression from differentiated to undifferentiated thyroid tumors: alterations in PI3K and MAPK pathways occur in nearly all undifferentiated tumors, with the majority of the cases harboring genetic alterations in both pathways (Hou et al., 2007).

To gain insights into how PI3K activation cooperates with activation of Ras in promoting thyroid cancer pathogenesis, the Kras mutant allele, G12D, was conditionally expressed in the thyroid epithelium through Cre-mediated deletion of a floxed STOP cassette preventing KrasG12D expression in mice that had already Pten deleted (Miller et al., 2009). Although each of these two pathways, alone, was unable to transform thyroid follicular cells, their simultaneous activation was highly oncogenic, leading to invasive, and metastatic follicular carcinomas (Miller et al., 2009). In particular, PI3K activation suppressed Kras-initiated feedback signals that uncouple MEK and ERK activation, thus inhibiting MAPK activity; in addition, PI3K and Kras cooperated to dramatically up-regulate cyclin D1 mRNA levels (Miller et al., 2009). Finally, combined pharmacologic inhibition of PI3K and MAPK completely abolished the growth of double-mutant transformed cell lines, providing a strong rationale for the dual targeting of these pathways in thyroid cancer (Miller et al., 2009).

Cell cycle progression is accomplished by a sequential and concerted activation of a family of serine-threonine kinases, named the cyclin-dependent kinases (CDKs). p2 $7^{\mathrm{Kip} 1}$ is an essential CDK inhibitor and plays a fundamental role in key cellular processes such as proliferation, differentiation, apoptosis, substrate adhesion, and motility. Downregulation of $\mathrm{p} 27^{\mathrm{Kip} 1}$ nuclear level or its cytosolic localization are always correlated with poor prognosis of numerous types of human epithelial and non-epithelial cancers (Borriello et al., 2011).

When analyzing the outcome of thyroid-specific $\mathrm{Pten}^{-/}$; $p 27^{-1}$ mice, the double-mutant animals exhibited a decrease of 
their survival, and all died by 6 months of age, with dramatically hyperplastic thyroids that caused dyspnea and prevented feeding (Antico-Arciuch et al., 2010). Interestingly, Pten ${ }^{-/-} ; p 27^{+/-}$ mutants had a mean survival of 58 weeks, a $25 \%$ reduction compared to $\mathrm{Pten}^{-/-} ; p 27^{+/+}$mice. While $\mathrm{Pten}^{-/-} ; p 27^{+/+}$females show a marked decrease in life span compared to single mutant males, these gender-based differences in survival were totally rescued by the reduction of $p 27$ gene dosage, suggesting that p27 is a relevant mediator of the effects of estrogen on thyroid tumor incidence (Antico-Arciuch et al., 2010). In fact, when we compared the proliferative index of thyroids from young, tumor-free Pten $^{-/-} ; p 27^{+/+}$and Pten ${ }^{-1-} ; p 27^{+1-}$ mice, we observed that loss of one $p 27$ allele in the males resulted in a larger proliferation increase than it did in the females. As a consequence, the gender differences in thyrocyte proliferation were considerably reduced in Pten ${ }^{-/} p 27^{+/-}$mice. Furthermore, Pten $^{-/-} ; p 27^{+/-}$ compound mutants survived long enough to develop adenomas and carcinomas (Antico-Arciuch et al., 2010). These compelling data strongly support a role for p27 as an important mediator of estrogen signaling in thyroid hyperproliferation and neoplastic transformation.

\section{REFERENCES}

Antico-Arciuch, V. G., Dima, M., Liao, X. H., Refetoff, S., and Di Cristofano, A. (2010). Cross-talk between PI3K and estrogen in the mouse thyroid predisposes to the development of follicular carcinomas with a higher incidence in females. Oncogene 29, 5678-5686.

Anzick, S. L., Kononen, J., Walker, R. L., Azorsa, D. O., Tanner, M. M., Guan, X. Y., Sauter, G., Kallioniemi, O. P., Trent, J. M., and Meltzer, P. S. (1997). AIB1, a steroid receptor coactivator amplified in breast and ovarian cancer. Science 277, 965-968.

Battista, S., Martelli, M. L., Fedele, M., Chiappetta, G., Trapasso, F., De Vita, G., Battaglia, C., Santoro, M., Viglietto, G., Fagin, J. A., and Fusco, A. (1995). A mutated p53 gene alters thyroid cell differentiation. Oncogene 11, 2029-2037.

Bollag, G., Hirth, P., Tsai, J., Zhang, J., Ibrahim, P. N., Cho, H., Spevak, W., Zhang, C., Zhang, Y., Habets, G., Burton, E. A., Wong, B., Tsang, G., West, B. L., Powell, B., Shellooe, R., Marimuthu, A., Nguyen, H., Zhang, K. Y., Artis, D. R., Schlessinger, J., Su, F., Higgins, B., Iyer, R., D’Andrea, K., Koehler, A., Stumm, M., Lin, P. S., Lee, R. J., Grippo, J., Puzanov, I., Kim, K. B., Ribas, A., Mcarthur, G. A., Sosman, J. A., Chapman, P. B., Flaherty, K. T., Xu, X., Nathanson, K. L., and Nolop, K. (2010). Clinical efficacy of a RAF inhibitor needs broad target blockade in BRAF-mutant melanoma. Nature 467, 596-599.

Bongarzone, I., Pierotti, M. A., Monzini, N., Mondellini, P., Manenti, G.,

\section{CONCLUSION}

Despite some shortcomings associated with a number of biological differences between mice and humans, the last 15 years have seen the development of a variety of genetically defined models of well differentiated thyroid tumors that have dramatically increased our knowledge of the key molecules and pathways involved in both neoplastic transformation and tumor progression. The challenge is now twofold: to extend these models to more aggressive tumor types (i.e., anaplastic carcinomas), in order to identify the specific mechanisms leading to loss of differentiation and increased metastatic potential; and to exploit these models and available cutting edge technology to pinpoint key molecular nodes that can be targeted in order to increase or restore therapeutic efficacy.

\section{ACKNOWLEDGMENTS}

Related work in the authors' laboratory has been supported by an NIH grant to Antonio Di Cristofano (CA128943) and by the Irma T. Hirschl Career Scientist Award. Unfortunately it was not possible to quote all relevant literature and we apologize for any omissions of pertinent research papers.

thyroid cancer in the adult mouse. Cancer Res. 71, 3863-3871.

Cheng, S. Y. (2000). Multiple mechanisms for regulation of the transcriptional activity of thyroid hormone receptors. Rev. Endocr. Metab. Disord. 1, 9-18.

Cho, J. Y., Sagartz, J. E., Capen, C. C., Mazzaferri, E. L., and Jhiang, S. M. (1999). Early cellular abnormalities induced by RET/PTC1 oncogene in thyroid-targeted transgenic mice. Oncogene 18, 3659-3665.

DeGroot, L. J., Kaplan, E. L., Mccormick, M., and Straus, F. H. (1990). Natural history, treatment, and course of papillary thyroid carcinoma. J. Clin. Endocrinol. Metab. 71, 414-424.

DeLellis, R. A. (2004). Pathology and Genetics of Tumours of Endocrine Organs. Lyon: IARC Press.

Dosaka-Akita, H., Hommura, F., Fujita, H., Kinoshita, I., Nishi, M., Morikawa, T., Katoh, H., Kawakami, Y., and Kuzumaki, N. (1998). Frequent loss of gelsolin expression in non-small cell lung cancers of heavy smokers. Cancer Res. 58, 322-327.

Eberhardt, N. L., Grebe, S. K., Mciver, B., and Reddi, H. V. (2010). The role of the PAX8/PPARgamma fusion oncogene in the pathogenesis of follicular thyroid cancer. Mol. Cell. Endocrinol. 321, 50-56.

Fagin, J. A. (2002). Minireview: branded from the start-distinct oncogenic initiating events may determine tumor fate in the thyroid. Mol. Endocrinol. 16, 903-911.

Fedele, M., Palmieri, D., Chiappetta, G., Pasquinelli, R., De Martino,
I., Arra, C., Palma, G., Valentino, T., Pierantoni, G. M., Viglietto, G., Rothstein, J. L., Santoro, M., and Fusco, A. (2009). Impairment of the p27kip1 function enhances thyroid carcinogenesis in TRK-T1 transgenic mice. Endocr. Relat. Cancer 16, 483-490.

Feunteun, J., Michiels, F., Rochefort, P., Caillou, B., Talbot, M., Fournes, B., Mercken, L., Schlumberger, M., and Monier, R. (1997). Targeted oncogenesis in the thyroid of transgenic mice. Horm. Res. 47, 137-139.

Flaherty, K. T., Puzanov, I., Kim, K. B., Ribas, A., Mcarthur, G. A., Sosman, J. A., O'Dwyer, P. J., Lee, R. J., Grippo, J. F., Nolop, K., and Chapman, P. B. (2010). Inhibition of mutated, activated BRAF in metastatic melanoma. N. Engl. J. Med. 363, 809-819.

Fonseca, E., Soares, P., CardosoOliveira, M., and Sobrinho-Simoes, M. (2006). Diagnostic criteria in well-differentiated thyroid carcinomas. Endocr. Pathol. 17, 109-117.

Frasca, F., Nucera, C., Pellegriti, G., Gangemi, P., Attard, M., Stella, M., Loda, M., Vella, V., Giordano, C., Trimarchi, F., Mazzon, E., Belfiore, A., and Vigneri, R. (2008). BRAF(V600E) mutation and the biology of papillary thyroid cancer. Endocr. Relat. Cancer 15, 191-205.

Fukushima, T., Suzuki, S., Mashiko, M., Ohtake, T., Endo, Y., Takebayashi, Y., Sekikawa, K., Hagiwara, K., and Takenoshita, S. (2003). BRAF mutations in papillary carcinomas of the thyroid. Oncogene 22, 6455-6457. 
Furuya, F., Lu, C., Willingham, M. C., and Cheng, S. Y. (2007). Inhibition of phosphatidylinositol 3-kinase delays tumor progression and blocks metastatic spread in a mouse model of thyroid cancer. Carcinogenesis 28, 2451-2458.

Fusco, A., and Santoro, M. (2007). 20 years of RET/PTC in thyroid cancer: clinico-pathological correlations. Arq. Bras. Endocrinol. Metabol. 51, 731-735.

Gimm, O., Dziema, H., Brown, J., Hoang-Vu, C., Hinze, R., Dralle, H., Mulligan, L. M., and Eng, C. (2001). Over-representation of a germline variant in the gene encoding RET co-receptor GFRalpha-1 but not GFRalpha-2 or GFRalpha3 in cases with sporadic medullary thyroid carcinoma. Oncogene 20, 2161-2170.

Giordano, T. J., Kuick, R., Thomas, D. G., Misek, D. E., Vinco, M., Sanders, D., Zhu, Z., Ciampi, R., Roh, M., Shedden, K., Gauger, P., Doherty, G., Thompson, N. W., Hanash, S., Koenig, R. J., and Nikiforov, Y. E. (2005). Molecular classification of papillary thyroid carcinoma: distinct BRAF, RAS, and RET/PTC mutation-specific gene expression profiles discovered by DNA microarray analysis. Oncogene 24, 6646-6656.

Giuffrida, D., and Gharib, H. (2000). Anaplastic thyroid carcinoma: current diagnosis and treatment. Ann. Oncol. 11, 1083-1089.

Greco, A., Pierotti, M. A., Bongarzone, I., Pagliardini, S., Lanzi, C., and Della Porta, G. (1992). TRK-T1 is a novel oncogene formed by the fusion of TPR and TRK genes in human papillary thyroid carcinomas. Oncogene 7, 237-242.

Grieco, M., Santoro, M., Berlingieri, M. T., Melillo, R. M., Donghi, R., Bongarzone, I., Pierotti, M. A., Della Porta, G., Fusco, A., and Vecchio, G. (1990). PTC is a novel rearranged form of the ret proto-oncogene and is frequently detected in vivo in human thyroid papillary carcinomas. Cell 60, 557-563.

Guigon, C. J., Fozzatti, L., Lu, C., Willingham, M. C., and Cheng, S. Y. (2010). Inhibition of mTORC1 signaling reduces tumor growth but does not prevent cancer progression in a mouse model of thyroid cancer. Carcinogenesis 31, 1284-1291.

Guigon, C. J., Zhao, L., Willingham, M. C., and Cheng, S. Y. (2009). PTEN deficiency accelerates tumour progression in a mouse model of thyroid cancer. Oncogene 28, 509-517.
Hou, P., Liu, D., Shan, Y., Hu, S., Studeman, K., Condouris, S., Wang, Y., Trink, A., El-Naggar, A. K., Tallini, G., Vasko, V., and Xing, M. (2007). Genetic alterations and their relationship in the phosphatidylinositol 3-kinase/Akt pathway in thyroid cancer. Clin. Cancer Res. 13, 1161-1170.

Huang, B. Y., Lin, J. D., Chao, T. C. Lin, K. J., Hseuh, C., and Tsang, N. M. (2011). Therapeutic outcomes of papillary thyroid cancer patients in different risk groups. Oncology 80, 123-129.

Ishizaka, Y., Shima, H., Sugimura, T., and Nagao, M. (1992). Detection of phosphorylated retTPC oncogene product in cytoplasm. Oncogene 7, 1441-1444.

Jhiang, S. M., Cho, J. Y., Furminger, T. L., Sagartz, J. E., Tong, Q., Capen, C. C., and Mazzaferri, E. L. (1998). Thyroid carcinomas in RET/PTC transgenic mice. Recent Results Cancer Res. 154, 265-270.

Jonklaas, J., Sarlis, N. J., Litofsky, D., Ain, K. B., Bigos, S. T., Brierley, J. D., Cooper, D. S., Haugen, B. R., Ladenson, P. W., Magner, J., Robbins, J., Ross, D. S., Skarulis, M., Maxon, H. R., and Sherman, S. I. (2006). Outcomes of patients with differentiated thyroid carcinoma following initial therapy. Thyroid 16, 1229-1242.

Kakudo, K., Bai, Y., Liu, Z., Li, Y., Ito, Y., and Ozaki, T. (2011). Classification of thyroid follicular cell tumors: with special reference to borderline lesions. Endocr. J. PMID: 21908930. [Epub ahead of print].

Kamiya, Y., Puzianowska-Kuznicka, M. Mcphie, P., Nauman, J., Cheng, S. Y., and Nauman, A. (2002). Expression of mutant thyroid hormone nuclear receptors is associated with human renal clear cell carcinoma. Carcinogenesis 23, 25-33.

Kaneshige, M., Kaneshige, K., Zhu, X., Dace, A., Garrett, L., Carter, T. A., Kazlauskaite, R., Pankratz, D. G., Wynshaw-Boris, A., Refetoff, S., Weintraub, B., Willingham, M. C., Barlow, C., and Cheng, S. (2000). Mice with a targeted mutation in the thyroid hormone beta receptor gene exhibit impaired growth and resistance to thyroid hormone. Proc. Natl. Acad. Sci. U.S.A. 97, 13209-13214.

Kato, Y., Ying, H., Willingham, M. C., and Cheng, S. Y. (2004). A tumor suppressor role for thyroid hormone beta receptor in a mouse model of thyroid carcinogenesis. Endocrinology 145, 4430-4438.
Kim, C. S., Furuya, F., Ying, H., Kato, Y., Hanover, J. A., and Cheng, S. Y. (2007a). Gelsolin: a novel thyroid hormone receptor-beta interacting protein that modulates tumor progression in a mouse model of follicular thyroid cancer. Endocrinology 148, 1306-1312.

Kim, C. S., Ying, H., Willingham, M. C., and Cheng, S. Y. (2007b). The pituitary tumor-transforming gene promotes angiogenesis in a mouse model of follicular thyroid cancer. Carcinogenesis 28, 932-939.

Kim, C. S., Vasko, V. V., Kato, Y. Kruhlak, M., Saji, M., Cheng, S. Y., and Ringel, M. D. (2005). AKT activation promotes metastasis in a mouse model of follicular thyroid carcinoma. Endocrinology 146, 4456-4463.

Kimura, E. T., Nikiforova, M. N., Zhu, Z., Knauf, J. A., Nikiforov, Y. E., and Fagin, J. A. (2003). High prevalence of BRAF mutations in thyroid cancer: genetic evidence for constitutive activation of the RET/PTC-RAS BRAF signaling pathway in papillary thyroid carcinoma. Cancer Res. 63 1454-1457.

Knauf, J. A., Ma, X., Smith, E. P. Zhang, L., Mitsutake, N., Liao, X. H., Refetoff, S., Nikiforov, Y. E., and Fagin, J. A. (2005). Targeted expression of BRAFV600E in thyroid cells of transgenic mice results in papillary thyroid cancers that undergo dedifferentiation. Cancer Res. 65, 4238-4245.

Knauf, J. A., Sartor, M. A., Medvedovic, M., Lundsmith, E., Ryder, M., Salzano, M., Nikiforov, Y. E., Giordano, T. J., Ghossein, R. A., and Fagin, J. A. (2011). Progression of BRAF-induced thyroid cancer is associated with epithelial-mesenchymal transition requiring concomitant MAP kinase and TGFbeta signaling. Oncogene 30, 3153-3162.

Kroll, T. G., Sarraf, P., Pecciarini, L., Chen, C. J., Mueller, E., Spiegelman, B. M., and Fletcher, J. A. (2000) PAX8-PPARgammal fusion oncogene in human thyroid carcinoma. Science 289, 1357-1360.

La Perle, K. M., Jhiang, S. M., and Capen, C. C. (2000). Loss of p53 promotes anaplasia and local invasion in ret/PTC1-induced thyroid carcinomas. Am. J. Pathol. 157, 671-677.

Lee, H. K., Driscoll, D., Asch, H., Asch, B., and Zhang, P. J. (1999). Downregulated gelsolin expression in hyperplastic and neoplastic lesions of the prostate. Prostate 40 14-19.
Liao, L., Kuang, S. Q., Yuan, Y., Gonzalez, S. M., O'Malley, B. W., and Xu, J. (2002). Molecular structure and biological function of the canceramplified nuclear receptor coactivator SRC-3/AIB1. J. Steroid Biochem. Mol. Biol. 83, 3-14.

Lin, K. H., Shieh, H. Y., Chen, S. L., and Hsu, H. C. (1999). Expression of mutant thyroid hormone nuclear receptors in human hepatocellular carcinoma cells. Mol. Carcinog. 26, 53-61.

LiVolsi, V. A. (2011). Papillary thyroid carcinoma: an update. Mod. Pathol. 24(Suppl. 2), S1-S9.

LiVolsi, V. A., and Baloch, Z. W. (2004). Follicular neoplasms of the thyroid: view, biases, and experiences. Adv. Anat. Pathol. 11, 279-287.

Lonard, D. M., and O'Malley, B. W. (2005). Expanding functional diversity of the coactivators. Trends Biochem. Sci. 30, 126-132.

Lu, C., Zhao, L., Ying, H., Willingham, M. C., and Cheng, S. Y. (2010) Growth activation alone is not sufficient to cause metastatic thyroid cancer in a mouse model of follicular thyroid carcinoma. Endocrinology 151, 1929-1939.

Maurer, G., Tarkowski, B., and Baccarini, M. (2011). Raf kinases in cancer-roles and therapeutic opportunities. Oncogene 30, 3477-3488.

Meier, C. A., Dickstein, B. M., Ashizawa, K., McClaskey, J. H., Muchmore, P., Ransom, S. C., Menke, J. B., Hao, E. H., Usala, S. J., Bercu, B. B., Cheng, S-Y., and Weintraub, B. D. (1992). Variable transcriptional activity and ligand binding of mutant beta $13,5,3^{\prime}$-triiodothyronine receptors from four families with generalized resistance to thyroid hormone. Mol. Endocrinol. 6, 248-258.

Melillo, R. M., Castellone, M. D., Guarino, V., De Falco, V., Cirafici, A. M., Salvatore, G., Caiazzo, F., Basolo, F., Giannini, R., Kruhoffer, M., Orntoft, T., Fusco, A., and Santoro, M. (2005). The RET/PTC-RAS-BRAF linear signaling cascade mediates the motile and mitogenic phenotype of thyroid cancer cells. J. Clin. Invest. 115, 1068-1081.

Mesa, C. Jr., Mirza, M., Mitsutake, N. Sartor, M., Medvedovic, M., Tomlinson, C., Knauf, J. A., Weber, G. F., and Fagin, J. A. (2006). Conditional activation of RET/PTC3 and BRAFV600E in thyroid cells is associated with gene expression profiles that predict a preferential role of BRAF in extracellular 
matrix remodeling. Cancer Res. 66, 6521-6529.

Miller, K. A., Yeager, N., Baker, K., Liao, X. H., Refetoff, S., and Di Cristofano, A. (2009). Oncogenic Kras requires simultaneous PI3K signaling to induce ERK activation and transform thyroid epithelial cells in vivo. Cancer Res. 69, 3689-3694.

Motti, M. L., Califano, D., Troncone, G., De Marco, C., Migliaccio, I., Palmieri, E., Pezzullo, L., Palombini, L., Fusco, A., and Viglietto, G. (2005). Complex regulation of the cyclin-dependent kinase inhibitor p27kipl in thyroid cancer cells by the PI3K/AKT pathway: regulation of p27kip1 expression and localization. Am. J. Pathol. 166, 737-749.

Nazarian, R., Shi, H., Wang, Q., Kong, X., Koya, R. C., Lee, H., Chen, Z., Lee, M. K., Attar, N., Sazegar, H., Chodon, T., Nelson, S. F., Mcarthur, G., Sosman, J. A., Ribas, A., and Lo, R. S. (2010). Melanomas acquire resistance to B-RAF(V600E) inhibition by RTK or N-RAS upregulation. Nature 468, 973-977.

Nucera, C., Nehs, M. A., Nagarkatti, S. S., Sadow, P. M., Mekel, M., Fischer, A. H., Lin, P. S., Bollag, G. E., Lawler, J., Hodin, R. A., and Parangi, S. (2011). Targeting BRAFV600E with PLX4720 displays potent antimigratory and anti-invasive activity in preclinical models of human thyroid cancer. Oncologist 16, 296-309.

Parrilla, R., Mixson, A. J., Mcpherson, J. A., Mcclaskey, J. H., and Weintraub, B. D. (1991). Characterization of seven novel mutations of the c-erbA beta gene in unrelated kindreds with generalized thyroid hormone resistance. Evidence for two "hot spot" regions of the ligand binding domain. J. Clin. Invest. 88, 2123-2130.

Pierotti, M. A., Bongarzone, I., Borello, M. G., Greco, A., Pilotti, S., and Sozzi, G. (1996). Cytogenetics and molecular genetics of carcinomas arising from thyroid epithelial follicular cells. Genes Chromosomes Cancer 16, 1-14.

Powell, D. J. Jr., Russell, J., Nibu, K., Li, G., Rhee, E., Liao, M., Goldstein, M., Keane, W. M., Santoro, M., Fusco, A., and Rothstein, J. L. (1998). The RET/PTC3 oncogene: metastatic solid-type papillary carcinomas in murine thyroids. Cancer Res. 58, 5523-5528.

Powell, D. J. Jr., Russell, J. P., Li, G., Kuo, B. A., Fidanza, V., Huebner, K., and Rothstein, J. L. (2001). Altered gene expression in immunogenic poorly differentiated thyroid carcinomas from RET/PTC3p53-/mice. Oncogene 20, 3235-3246.

Puzianowska-Kuznicka, M., Krystyniak, A., Madej, A., Cheng, S. Y., and Nauman, J. (2002). Functionally impaired TR mutants are present in thyroid papillary cancer. J. Clin. Endocrinol. Metab. 87, 1120-1128.

Ramaswamy, S., Ross, K. N., Lander, E. S., and Golub, T. R. (2003). A molecular signature of metastasis in primary solid tumors. Nat. Genet. 33, 49-54.

Russell, J. P., Engiles, J. B., and Rothstein, J. L. (2004). Proinflammatory mediators and genetic background in oncogene mediated tumor progression. J. Immunol. 172, 4059-4067.

Russell, J. P., Powell, D. J., Cunnane, M., Greco, A., Portella, G., Santoro, M., Fusco, A., and Rothstein, J. L. (2000). The TRK-T1 fusion protein induces neoplastic transformation of thyroid epithelium. Oncogene 19, 5729-5735.

Ryder, M., Ghossein, R. A., RicarteFilho, J. C., Knauf, J. A., and Fagin, J. A. (2008). Increased density of tumor-associated macrophages is associated with decreased survival in advanced thyroid cancer. Endocr. Relat. Cancer 15, 1069-1074.

Saji, M., Narahara, K., Mccarty, S. K., Vasko, V. V., La Perle, K. M., Porter, K., Jarjoura, D., Lu, C., Cheng, S. Y., and Ringel, M. D. (2011). Aktl deficiency delays tumor progression, vascular invasion, and distant metastasis in a murine model of thyroid cancer. Oncogene 30, 4307-4315.

Salerno, P., De Falco, V., Tamburrino, A., Nappi, T. C., Vecchio, G., Schweppe, R. E., Bollag, G., Santoro, M., and Salvatore, G. (2010). Cytostatic activity of adenosine triphosphatecompetitive kinase inhibitors in BRAF mutant thyroid carcinoma cells. J. Clin. Endocrinol. Metab. 95, 450-455.

Santoro, M., Chiappetta, G., Cerrato, A., Salvatore, D., Zhang, L., Manzo, G., Picone, A., Portella, G., Santelli, G., Vecchio, G., and Fusco, A. (1996). Development of thyroid papillary carcinomas secondary to tissue-specific expression of the RET/PTC1 oncogene in transgenic mice. Oncogene 12, 1821-1826.

Santoro, M., Dathan, N. A., Berlingieri, M. T., Bongarzone, I., Paulin, C., Grieco, M., Pierotti, M. A., Vecchio, G., and Fusco, A. (1994). Molecular characterization of RET/PTC3; a novel rearranged version of the RETproto-oncogene in a human thyroid papillary carcinoma. Oncogene 9, 509-516.
Santoro, M., Melillo, R. M., Grieco, M. Berlingieri, M. T., Vecchio, G., and Fusco, A. (1993). The TRK and RET tyrosine kinase oncogenes cooperate with ras in the neoplastic transformation of a rat thyroid epithelial cell line. Cell Growth Differ. 4, 77-84.

Sariola, H., and Saarma, M. (2003). Novel functions and signalling pathways for GDNF. J. Cell. Sci. 116, 3855-3862.

Schlumberger, M. J. (1998). Papillary and follicular thyroid carcinoma. $N$. Engl. J. Med. 338, 297-306.

Shi, Y. F., Zou, M. J., Schmidt, H., Juhasz, F., Stensky, V., Robb, D., and Farid, N. R. (1991). High rates of ras codon 61 mutation in thyroid tumors in an iodide-deficient area. Cancer Res. 51, 2690-2693.

Suh, N., Wang, Y., Williams, C. R. Risingsong, R., Gilmer, T., Willson, T. M., and Sporn, M. B. (1999). A new ligand for the peroxisome proliferator-activated receptor-gamma (PPAR-gamma), GW7845, inhibits rat mammary carcinogenesis. Cancer Res. 59, 5671-5673.

Suzuki, H., Willingham, M. C., and Cheng, S. Y. (2002). Mice with a mutation in the thyroid hormone receptor beta gene spontaneously develop thyroid carcinoma: a mouse model of thyroid carcinogenesis. Thyroid 12, 963-969.

Tanaka, M., Mullauer, L., Ogiso, Y. Fujita, H., Moriya, S., Furuuchi, K., Harabayashi, T., Shinohara, N., Koyanagi, T., and Kuzumaki, N. (1995). Gelsolin: a candidate for suppressor of human bladder cancer. Cancer Res. 55, 3228-3232.

Torregrossa, L., Giannini, R., Borrelli, N., Sensi, E., Melillo, R. M., Leocata, P., Materazzi, G., Miccoli, P., Santoro, M., and Basolo, F. (2011). CXCR4 expression correlates with the degree of tumor infiltration and BRAF status in papillary thyroid carcinomas. Mod. Pathol. PMID: 21909080. [Epub ahead of print].

Torres-Arzayus, M. I., Font De Mora, J., Yuan, J., Vazquez, F., Bronson, R., Rue, M., Sellers, W. R., and Brown, M. (2004). High tumor incidence and activation of the PI3K/AKT pathway in transgenic mice define AIB1 as an oncogene. Cancer Cell 6, 263-274.

Tuveson, D. A., Shaw, A. T., Willis, N. A., Silver, D. P., Jackson, E. L., Chang, S., Mercer, K. L., Grochow, R., Hock, H., Crowley, D., Hingorani, S. R., Zaks, T., King, C., Jacobetz, M. A., Wang, L., Bronson, R. T., Orkin, S. H., Depinho, R. A., and
Jacks, T. (2004). Endogenous oncogenic K-ras(G12D) stimulates proliferation and widespread neoplastic and developmental defects. Cancer Cell 5, 375-387.

Vitagliano, D., Portella, G., Troncone, G., Francione, A., Rossi, C., Bruno, A., Giorgini, A., Coluzzi, S., Nappi, T. C., Rothstein, J. L., Pasquinelli, R., Chiappetta, G., Terracciano, D., Macchia, V., Melillo, R. M., Fusco, A., and Santoro, M. (2006). Thyroid targeting of the $\mathrm{N}$-ras(Gln61Lys) oncogene in transgenic mice results in follicular tumors that progress to poorly differentiated carcinomas. Oncogene 25, 5467-5474.

Weiss, R. E., and Refetoff, S. (2000). Resistance to thyroid hormone. Rev. Endocr. Metab. Disord. 1, 97-108.

Williams, E. D., Abrosimov, A., Bogdanova, T., Demidchik, E. P., Ito, M., Livolsi, V., Lushnikov, E., Rosai, J., Sidorov, Y., Tronko, M. D., Tsyb, A. F., Vowler, S. L., and Thomas, G. A. (2004). Thyroid carcinoma after Chernobyl latent period, morphology and aggressiveness. Br. J. Cancer 90, 2219-2224.

Winston, J. S., Asch, H. L., Zhang, P. J., Edge, S. B., Hyland, A., and Asch, B. B. (2001). Downregulation of gelsolin correlates with the progression to breast carcinoma. Breast Cancer Res. Treat. 65, 11-21.

Xing, M. (2010). Genetic alterations in the phosphatidylinositol-3 kinase/Akt pathway in thyroid cancer. Thyroid 20, 697-706.

Yan, J., Tsai, S. Y., and Tsai, M. J. (2006). SRC-3/AIB1: transcriptional coactivator in oncogenesis. Acta Pharmacol. Sin. 27, 387-394.

Yeager, N., Brewer, C., Cai, K. Q., $\mathrm{Xu}, \mathrm{X}$. X., and Di Cristofano, A. (2008). Mammalian target of rapamycin is the key effector of phosphatidylinositol-3-OHinitiated proliferative signals in the thyroid follicular epithelium. Cancer Res. 68, 444-449.

Yeager, N., Klein-Szanto, A., Kimura, S., and Di Cristofano, A. (2007). Pten loss in the mouse thyroid causes goiter and follicular adenomas: insights into thyroid function and Cowden disease pathogenesis. Cancer Res. 67, 959-966.

Ying, H., Willingham, M. C., and Cheng, S. Y. (2008). The steroid receptor coactivator-3 is a tumor promoter in a mouse model of thyroid cancer. Oncogene 27, 823-830.

Zafon, C., Obiols, G., Baena, J. A., Castellvi, J., Dalama, B., and Mesa, J. (2012). Preoperative thyrotropin serum concentrations gradually increase from benign thyroid 
nodules to papillary thyroid microcarcinomas then to papillary thyroid cancers of larger size. J. Thyroid Res. 2012, 530721.

Conflict of Interest Statement: The authors declare that the research was conducted in the absence of any commercial or financial relationships that could be construed as a potential conflict of interest.

Received: 27 November 2011; paper pending published: 12 December 2011; accepted: 30 December 2011; published online: 10 January 2012.
Citation: Russo MA, Arciuch VGA and Di Cristofano A (2012) Mouse models of follicular and papillary thyroid cancer progression. Front. Endocrin. 2:119. doi: 10.3389/fendo.2011.00119

This article was submitted to Frontiers in Thyroid Endocrinology, a specialty of Frontiers in Endocrinology.
Copyright $\odot 2012$ Russo, Arciuch and Di Cristofano. This is an open-access article distributed under the terms of the Creative Commons Attribution Non Commercial License, which permits noncommercial use, distribution, and reproduction in other forums, provided the original authors and source are credited. 